\title{
O ESPAÇO DOS CABOCOLINHOS: DA MANIFESTAÇÃO CÊNICA À GEOGRAFIA
}

\author{
Suzete Câmara da Silva'; Marinalva Nicácio de Moura² ${ }^{1}$ Jorge Alberto de Lima Júnior ${ }^{3}$; Jonilson de Souza \\ Figueiredo $^{4}$ \\ ${ }^{1,2,3}$ Instituto Federal do Rio Grande do Norte. \\ ${ }^{4}$ Universidade do Estado do Rio Grande do Norte \\ susilva_oi@yahoo.com.br ${ }^{1}$, marimoura5@hotmail.com ${ }^{2}$
}

Artigo submetido em fevereiro/2013 e aceito em dezembro/2013

\section{RESUMO}

O interesse pelo trabalho surgiu a partir das discussões desenvolvidas na disciplina Arte e Educação, do curso de Licenciatura Plena em Geografia oferecido pelo Instituto Federal de Educação, Ciência e Tecnologia do Rio Grande do Norte (IFRN), Campus Natal-Central, buscando por meio do diálogo entre as áreas uma proposta pedagógica interdisciplinar entre os estudos geográficos e o espetáculo cênico dos cabocolinhos. Compreender tal folguedo enquanto representação de parte das etnias formadoras da sociedade brasileira dada a importância e a contribuição étnica cultural dos indígenas para a formação do espaço brasileiro cuja dança, enquanto representada para um público constitui-se como apresentação cênica, sendo o foco do presente artigo; além de serem os primeiros habitantes de nossas terras e por possuir uma manifestação que represente alguns aspectos de sua cultura em forma de dança no município de Ceará Mirim, única do Estado. Esse estudo será possível a partir da articulação do espaço do geógrafo ao espaço do espetáculo cênico, utilizando uma análise exploratória que reúne revisão de literatura referente aos conceitos utilizados, bem como coleta de dados preliminares que decorrem de entrevistas e coleta de dados secundários a partir de pesquisas documentais. O trabalho fornecerá estratégias que contribuirão para a compreensão dos conceitos e para futuras práticas docentes.

PALAVRAS-CHAVE: Teatro, Geografia, Interdisciplinaridade, Espaço.

\section{THE SPACE OF CABOCOLINHOS: THE SCENIC MANIFESTATION TO GEOGRAPHY}

\section{ABSTRACT}

The Interest for work emerged of the discussions carried out in Art and education, discipline of Full Degree in Geography course offered by Instituto Federal de Educação, Ciência e Tecnologia do Rio Grande do Norte (IFRN), Campus Natal-Central, looking for through of the dialogue between the areas a pedagogical proposal, interdisciplinarity between geographic studies and the scenic spectacle of cabocolinhos. Understand such merriment as part of their ethnicity-representation of Brazilian society in view of the importance and the ethnic cultural contribution of indigenous to the brazilian space whose formation dance, as represented to an audience is as scenic presentation, being the focus of this article; in
\end{abstract}

addition to being the first inhabitants of our land and by possessing a manifestation that represent some aspects of its culture in dance form in the municipality of Ceará Mirim, unique in the State. This study will be possible from the articulation of the geographer to the space of scenic spectacle, using an exploratory analysis that brings together literature revision regarding concepts used, as well as collecting primary data resulting from interviews and secondary data collection from documentary research. The work will provide strategies that will contribute to the understanding of the concepts and practices for future teachers.

KEYWORDS: Theater, Geography, Interdisciplinary, Space. 


\section{O ESPAÇO DOS CABOCOLINHOS: DA MANIFESTAÇÃO CÊNICA A GEOGRAFIA}

\section{INTRODUÇÃO}

O Rio Grande do Norte, assim como todo Brasil, apresenta uma grande diversidade cultural, resultado da contribuição das três etnias: brancos, negros e índios. Tal contribuição resultou na diversidade de comidas, hábitos, vestimentas, religiões e danças, esta foco do presente trabalho. Portanto, são os três formadores da sociedade brasileira. Entretanto quem são os donos das terras "encontradas" pelos brancos e o fim da labuta do negro?

A maior parte das terras conquistadas no século XVI estava na América, já habitada por um número bastante considerável de povos, incialmente, chamados autóctones que quer dizer originários da própria terra, que passaram, posteriormente, a ser conhecidos de indígenas cuja diversidade cultural foi afetada negativamente pelo processo de colonização que os europeus lhe impuseram, havendo até dizimação total de alguns povos. Um dos passos para a efetivação da colonização adotada foi a catequese como podemos observar na Figura 1 abaixo, em que é evidenciada a realização da primeira missa dos povos indígenas em terras brasileiras.

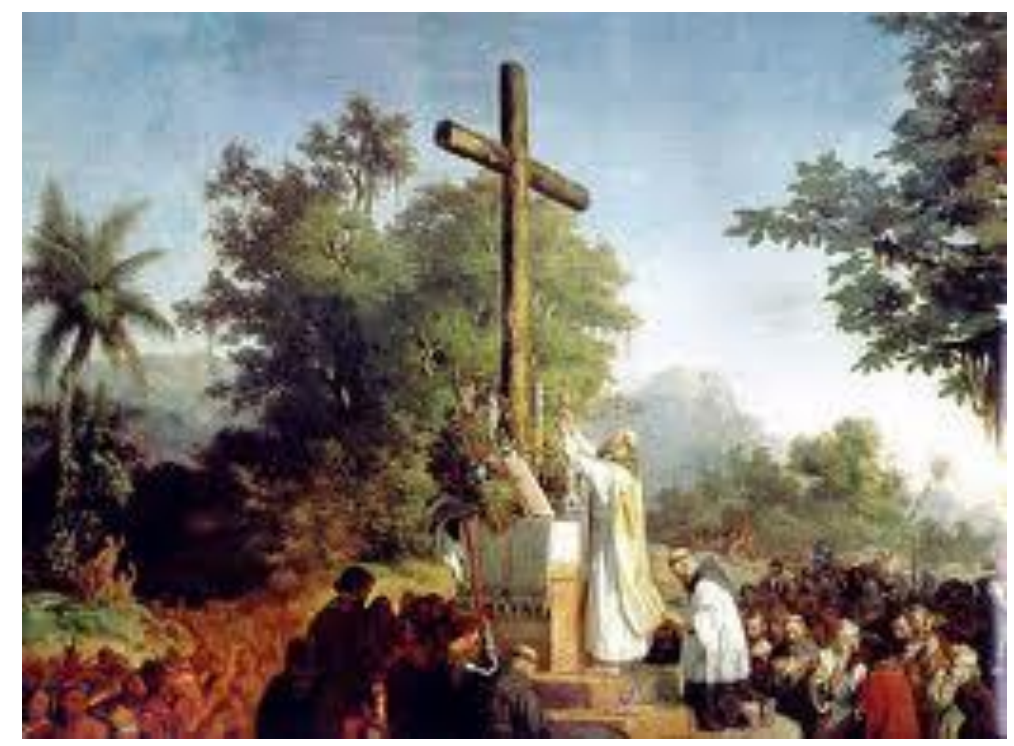

FIGURA 1- Primeira missa catequética do índio no Brasil. Fonte: RAMOS (2011).

A colonização brasileira se deu a custa dos índios que foram escravizados e mortos ao resistir. Além disso, o isolamento conferiu-lhes a falta de imunidades a doenças trazidas pelos europeus que foram devastadoras. Povos, culturas e idiomas foram perdidos. A época da chegada dos portugueses somam-se cerca de 4 milhões de indígenas (TAMDJIAN; MENDES, 2005). Hoje, segundo a Fundação de Nacional do Índio- FUNAI (2005) dados do censo 2010 do IBGE, têm-se apenas 817 mil índios. Porém, observa-se um crescimento desde a década de 1980, devido a marcos legais que tem por objetivo legitimar os direitos humanos desses povos.

Ao analisarmos a Figura 2 a seguir, podemos aferir esse quantitativo da época a partir de como esteve distribuído espacialmente no continente latino-americano as mais diversas etnias indígenas e que infelizmente com o chamado pós-colonialismo, esses números ganharam 
menores proporções e uma nova configuração nesses territórios, justificado pelos inúmeros massacres em busca de conquista de novas terras, exploração da mão de obra, além do descontrole para com a extração dos recursos naturais disponíveis, com o objetivo de fazer o escoamento para as sedes administrativas das colônias.

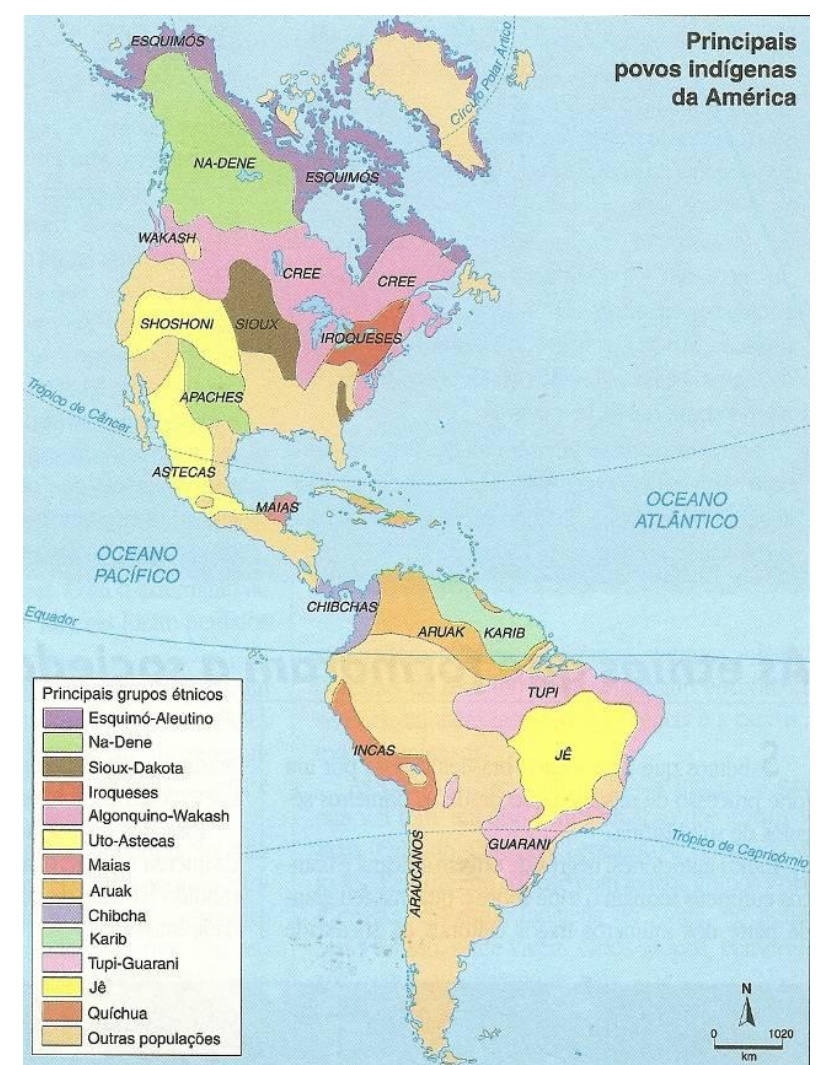

FIGURA 2- Distribuição espacial do índio na América Latina. Fonte: TAMDJIAM; MENDES, (2005).

Mesmo assim, os índios ainda hoje são alvos de preconceitos e são perseguidos por muitos fazendeiros, que invadem suas terras e tentam expulsá-los. Apenas com os Irmãos Vilas Boas é que as preocupações com os povos indígenas ganharam força. A participação na gestão da FUNAI foi importante para defesa de seus interesses, visto que foi um órgão criado com a finalidade de fazer o monitoramento, proteção dos direitos e articulação de políticas públicas para as minorias.

\section{CABOCOLINHOS: ENTRE A ARTE E A GEOGRAFIA}

A cultura indígena é marcante em nosso dia a dia, como, por exemplo, das palavras de origem tupi presentes em nosso vocabulário: pipoca, embira, tapioca, Ubatuba, entre outras. A herança dos índios pode ser constatada ainda na utilização de inúmeras ervas antes conhecida apenas por eles. A culinária foi outra grande influência dos índios com a utilização, por exemplo, em larga escala de milho e mandioca. Sem falar nos rituais que envolvem danças e espiritualidade. Suas vestimentas em rituais envolvem penas e outros materiais extraídos da natureza. 
Dada a importância e a contribuição étnica cultural dos indígenas para a formação do espaço brasileiro cuja dança, enquanto representada para um público se constituindo em apresentação teatral, será foco da presente pesquisa; além de serem os primeiros habitantes de nossas terras e por possuir uma manifestação que represente alguns aspectos de sua cultura em forma de Dança encenada por um grupo chamado Cabocolinhos no município de Ceará Mirim, única do Estado do Rio Grande do Norte, faz-se necessário compreender tal folguedo enquanto representação de parte das etnias formadoras da sociedade brasileira.

Entretanto, segundo Araújo (2003) deve-se prestar atenção na forma como manifestações espetaculares, como o bumba meu boi, a chegança, o pastoril, entre outras, são nomeadas, podendo ser apontadas como folclóricas, populares ou pitorescas, dependendo de quem as observe. O risco que se corre é utilizar tais qualitativos de forma pejorativa. O que por vezes pode parecer estranho a um cultura é totalmente aceitável em outra. Daí o conceito de cultura ser permeado por certas pessoalidades e especificidades espaciais.

Assim não se devem confundir apresentações cênicas com teatro. Dessa forma, esclarece Araújo (2003) que a palavra espetacular vem do latim especulum, que significa feito para ser visto. Neste sentido, todas as manifestações humanas que envolvem uma ação humana e seu espectador, podem ser classificadas como espetaculares. Portanto, tudo pode ser espetacular, mas nem tudo é teatro como o caso da missa que mesmo apresentando algumas estruturas parecidas com o teatro, não recebem os mesmos nomes, nem tem toda estrutura própria.

O teatro, portanto, segundo Ubersfeld (1979) é um espaço em que há troca de olhares entre quem olha e quem é olhado, além de haver uma delimitação espacial. Nesse sentido, os Cabocolinhos se enquadram nesse contexto visto que suas apresentações ocorrem em espaços delimitados, próprios para sua apresentação, e que permitem essa troca de olhares.

O espaço, nesse contexto, torna-se fundamental. Para as expressões dos folguedos, já que é possível encontrar nele os elementos teatrais, assumindo essa configuração por exemplo: o espaço dramático, construído pelo espectador ou pelo leitor. É o espaço da ficção. Já o espaço cênico é visível e se concretiza na encenação. Tais conceitos e delimitações nos ajudam a desenvolver a criticidade e a compreensão, neste caso, representados pelos cabocolinhos, quanto a aspectos e princípios da vida indígena como liderança e a vida em comunidade, ao ver seus espaços bem distribuídos na apresentação/representação e ao mesmo tempo, faz-se um paralelo com o espaço geográfico.

Além disso, é possível considerar ainda que para o Geógrafo Tuan (1983) o espaço é liberdade, é área das possibilidades e, portanto, toma uma conotação de localização relativa, entretanto passível de delimitação. Pode, assim, haver espaço demarcado. É o que ocorre quando da apresentação dos cabocolinhos. Há uma demarcação, uma delimitação, um espaço que se configura cênico, dramático e geográfico ao mesmo tempo. E ainda, no aspecto geográfico os índios possuem uma distribuição diferenciada no espaço brasileiro, porém bem delimitada garantida pela Constituição de 1988. Fica evidente uma proposta pedagógica educacional que pode ser foco de estudos posteriores.

É necessário a esta altura compreender como está organizada tal manifestação popular com suas características que se enquadram na forma de arte, teatro. Segundo o folclorista Edison Carneiro (1974), a origem de nossas danças folclóricas é movida pelas seguintes inspirações: a luta contra o infiel, a tragédia do mar, e o nascimento de Cristo, morte e ressurreição. Nos 
caboclinhos, ainda segundo o autor, a inspiração se encontra na morte e ressurreição, pois há um personagem que morre e ressuscita que é o filho do cacique, ressuscitado pelo Pajé da Tribo.

A terminologia da Comissão Nacional do Folclore (CNF) denomina de folguedo popular, o grupo que tem estrutura complexa, com mestre, dançadores, personagens, indumentária determinada, elementos tradicionais, ensaios, parte dramática, e grupo fechado, fixo. Elementos presentes nos Cabocolinhos e também característicos e presentes no teatro.

Segundo Cascudo (1972), Cabocolinhos é uma dança inspirada nos usos e costumes dos índios que ao som do arco e da flecha, com acompanhamento de instrumentos de sopro como flautas e pífanos, os integrantes do grupo executam vários movimentos coreográficos com saltos específicos e próprios, trocando pés, divididos em duas filas, imitando ataque e defesa, não existindo fala e com a gesticulação abundante. A movimentação depende da melodia que varia de lenta a rápida. Os espaços de apresentações são os mais variados. Antigamente era muito tradicional na Festa da Padroeira e no Carnaval do município, hoje suas apresentações também acorrem em movimentos, festas ou feiras alusivas a cultura. Também são conhecidos como Cabocolinhos da Rua da TELERN. Na Figura 3 fica visível o espaço dos cabocolinhos.

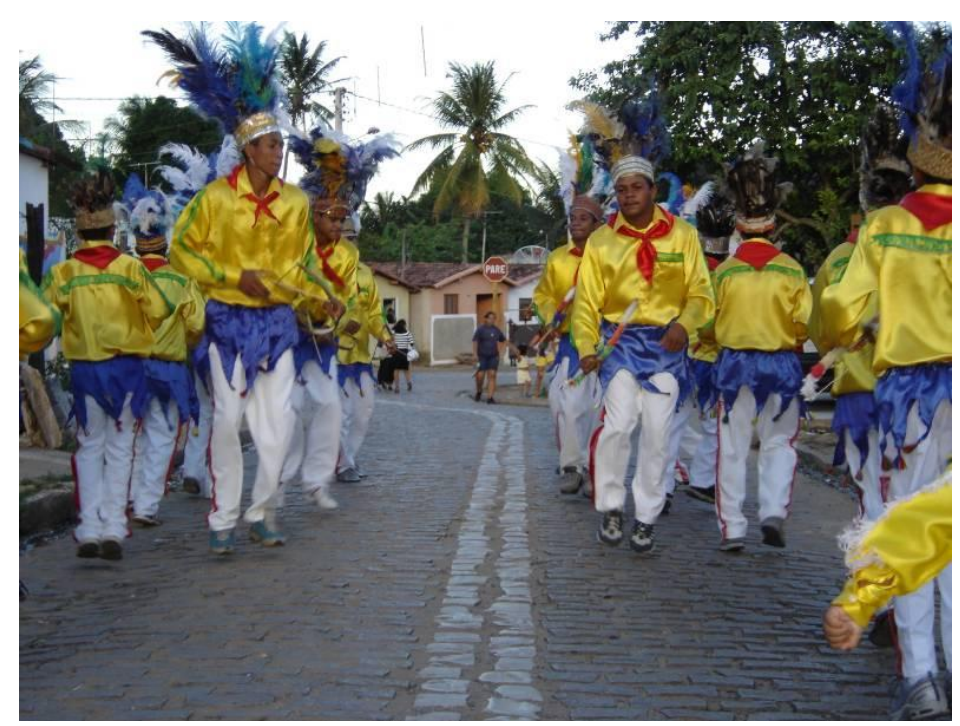

FIGURA 3- Apresentação dos Cabocolinhos em via pública. Fonte: MACHADO (2012).

Tradicional no município desde 1952, os Cabocolinhos de Ceará-Mirim, podem ser considerados um grupo ímpar neste gênero no Estado do RN. Segundo Gurgel (2001) atualmente o único grupo folclórico Cabocolinho existente em atuação no Rio Grande do Norte. Todavia, é importante ressaltar a existência de grupos Cabocolinhos na cidade de Natal-RN, caracterizados como "tribos de índios" voltados para apresentações no período carnavalesco. Esses grupos estão localizados nos bairros das Rocas, Mãe Luiza e Redinha. 


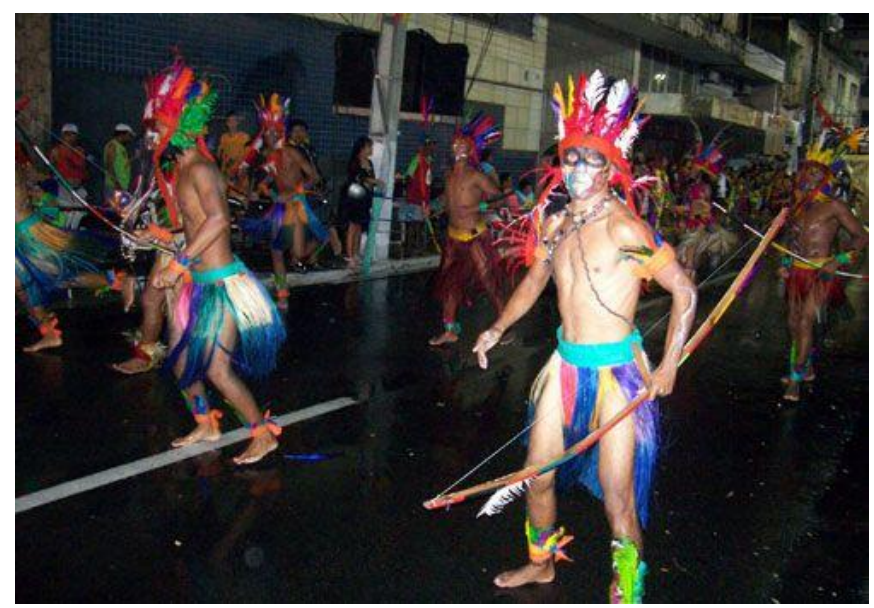

FIGURA 4- Apresentação das tribos de índios no carnaval em Natal-RN. Fonte: ARRUDA (2011).

Segundo o senhor Severino Roberto (BIRICO) presidente atual do grupo e mestre, quando seu pai chegou ao município, por volta dos anos de 1920, já havia o grupo na rua. Por vários anos, teve a frente o mestre Déo, que só deixou o grupo por falecimento ocorrido em 1995 aos 72 anos. Segundo Gurgel (2001), após a morte de "seu" Déo, os Cabocolinhos dissolveram-se, reorganizando-se, posteriormente sob novo comando. Foram três anos de luto sem se apresentar. Apenas em 1999 após reunião de integrantes é que ficou decidido que o grupo retomaria as suas apresentações.

Os espaços de cada um são bem demarcados, corroborando com os conceitos antes explicitados na Geografia e nas Artes Cênicas, além disso, as funções também são demarcadas como se pode observar no quadro 1 . O mestre é a representação do chefe indígena.

Segundo os "brincantes", mestre é aquele que organiza as danças com o apito, e guia é o responsável por puxar a dança de seu cordão e dizer as loas. Dentro do grupo existe uma certa hierarquia que divide os membros em funções específicas, as quais vão sendo conquistadas gradativamente de um estágio menor, passando pelo "peró-mingu" até o "mestre". Quando se entra no grupo com pouca idade, brinca-se no "rabo de cordão", ou seja, no final da fila e com o tempo se vai chegando à frente do grupo (FRANÇA, 2003, p. 34).

QUADRO 1- Personagens e suas funções nos Cabocolinhos.

\begin{tabular}{|c|r|}
\hline PERSONAGEM & FUNÇÃO \\
\hline MATROÁ & $\begin{array}{r}\text { tem a função de comandar o desfile, deve sair na frente do desfile uns vinte a quarenta } \\
\text { metros para ver se vem carro, e se as porta-bandeiras estão dançando direito. }\end{array}$ \\
\hline PORTA-BANDEIRA & tem a função de mostrar dançando a bandeira do grupo. \\
\hline FISCAIS & têm a função de proibir a entrada de pessoas estranhas nos cordões. \\
\hline BATEDORES & têm a função de tocar os bombos. \\
\hline GAITEIRO & é o responsável por fazer os toques. \\
\hline MESTRE & organiza as danças com o apito. \\
\hline PERÓ-MINGU & fica no rabo da fila, e sua função é terminar a parte de guerra dizendo uma loa. \\
\hline MARUJO & componente dos cordões (dançarino). \\
\hline GUIA & tem a função de puxar a dança de seu cordão e dizer as loas. \\
\hline PRESIDENTE & $\begin{array}{r}\text { sua função é arrumar meios para confeccionar as fantasias. No desfile a sua função é dançar } \\
\text { no meio dos cordões para ajudar o mestre, sendo dessa forma contra-mestre. }\end{array}$ \\
\hline
\end{tabular}

Fonte: Adaptado de França (2003). 
Os integrantes somam 42, sendo 34 participantes do sexo masculino e 08 do sexo feminino e estas têm atividades caracterizadas como de mulher, como costurar, passar roupas e porta-bandeira. O integrante mais velho tem 60 anos, é gaiteiro; e, o mais novo tem 08 anos e é porta-bandeira. A predominância dos participantes encontra-se situada na faixa etária entre 11 e 30 anos, demonstrando a supremacia dos jovens no grupo, apesar da resistência inicial quando da retomada do grupo. O mínimo de idade para participar é de 7 anos, e o máximo não é determinado, não possui limite. Os integrantes, a organização e a caracterização dos mesmos são evidenciados nas Figuras 5 e 6 respectivamente.

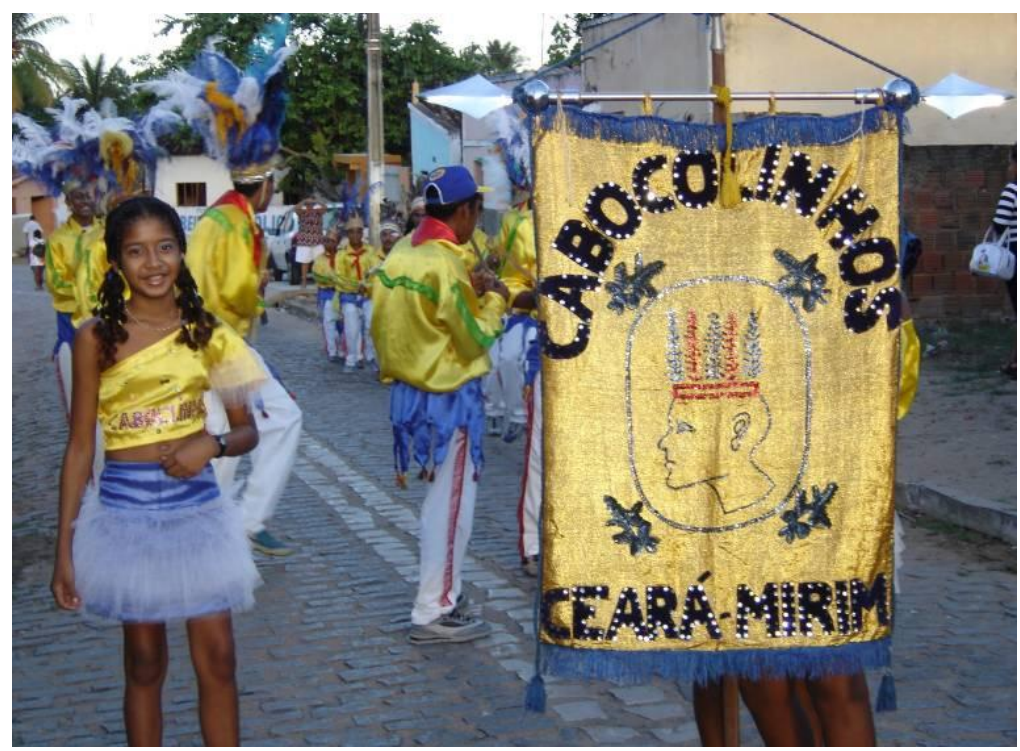

FIGURA 5- A participação feminina jovem e o estandarte do grupo. Fonte: MACHADO (2012).

A roupa utilizada pelos Cabocolinhos de Ceará-Mirim, ao contrário dos índios de Natal, têm poucos detalhes, porém não menos característica e representativa. O tecido usado é cetim. São três jogos de camisas, uma amarela, uma azul e uma verde cujo motivo pelo qual foram escolhidas tais cores não se sabe. A vestimenta fica completa com calça e uma espécie de tanga sobre esta. O calçado é tênis, e na cabeça usam um cocar de papelão coberto com penas e enfeites. Antes era composta por uma calçola (calça no meio da perna), feita com tecido de flanela, penas no tornozelo e nos punhos. 


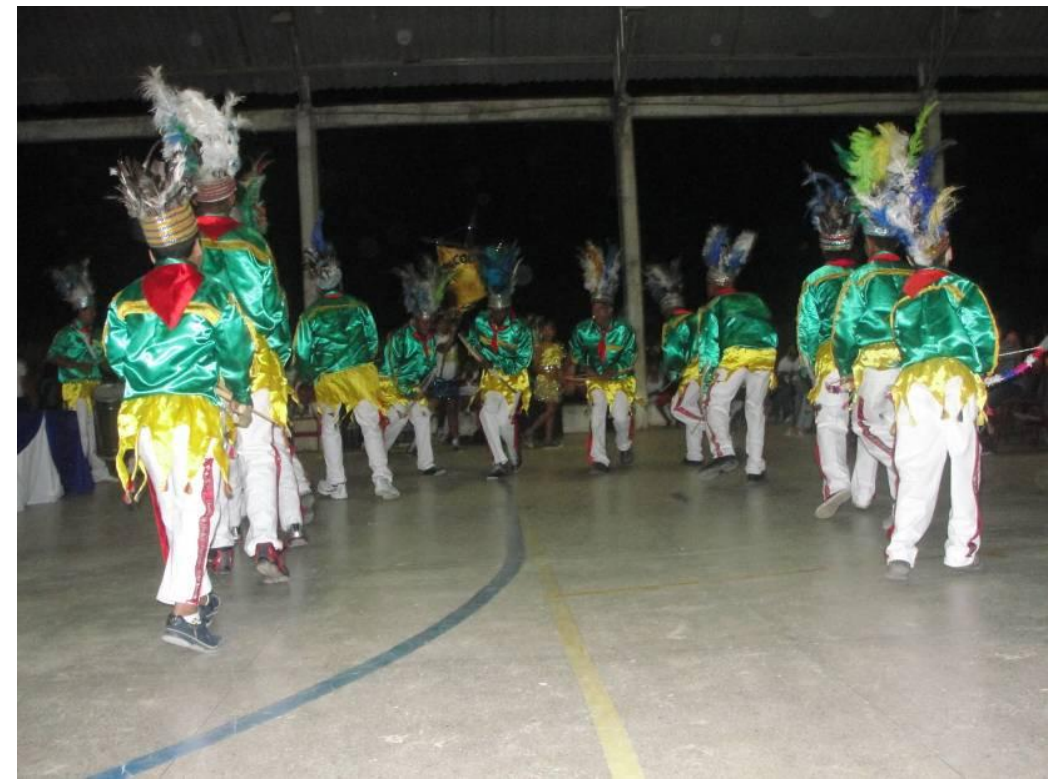

FIGURA 6- Apresentação dos Cabocolinhos com a segunda cor da vestimenta: verde. Fonte: MACHADO (2012).

Assim como cada participante do grupo tem uma função, alguns são responsáveis pelos instrumentos e seus sons. O Estandarte fica com as mulheres a frente do grupo e os homens que dançam ficam com o arco e flecha. Segue no quadro 2, a estrutura dos apetrechos e sua características.

QUADRO 2- Apetrechos do grupo cabocolinhos

\begin{tabular}{|c|c|}
\hline $\begin{array}{l}\text { NOME DO } \\
\text { APETRECHO }\end{array}$ & CARACTERÍSTICAS \\
\hline Estandarte & $\begin{array}{l}\text { Feito com tecido de veludo e enfeitado com lantejoulas. Possui o desenho de dois pássaros de } \\
\text { frente um para o outro. O pássaro é cabocolinho (o antigo), o novo possui o desenho da } \\
\text { cabeça de um índio. }\end{array}$ \\
\hline Apito & É de plástico. É o mesmo apito usado pelo guarda de trânsito. \\
\hline Flecha & $\begin{array}{l}\text { É feita de madeira que é retirada da mata, e linha. É enfeitada com papel de seda azul, } \\
\text { amarelo, verde, vermelho e branco. }\end{array}$ \\
\hline Arco & $\begin{array}{c}\text { É feito de cipó raspado, e é enfeitado com papel de seda branco. É usado atravessado em cruz } \\
\text { no corpo. }\end{array}$ \\
\hline Gaita & $\begin{array}{l}\text { É feita de metal. Possui quatro orifícios e é afinada com cera de um determinado mosquito, } \\
\text { pois dizem que a cera da abelha se desgasta mais rápido. }\end{array}$ \\
\hline Bombo & $\begin{array}{l}\text { Instrumento de percussão muito utilizado em bandas de música. É feito de metal, antes era de } \\
\text { compensado. }\end{array}$ \\
\hline
\end{tabular}

Fonte: França (2003).

Em conversa com um dos participantes e com o gaiteiro dos Cabocolinhos, Marinaldo Marques (Miro), eles relatam que os ensaios são realizados com o intuito de aprofundar ainda mais as danças para aqueles que ainda têm dificuldades e ao mesmo tempo manter certa sincronia com os novos e antigos bailados e toques, fazendo com que sejam mantidos os ritmos, 
repertorio e danças da geração passada. Eles são realizados de acordo com a disponibilidade de cada componente, sendo realizados no mínimo 1 vez por semana. Com duração de no máximo 2 horas. As melodias são criadas pelos próprios gaiteiros do grupo que são preparadas com muito esforço, ensaio e atenção tendo em vista que são criadas sem acordes nem cifras apenas com a própria capacidade sem perder de vista o ritmo original que pareça com as expressões indígenas. Afirma Miro: "seguimos uma sequência de melodias de geração em geração onde eu ouvi e aprendi de meu pai, que já ouviu e aprendeu do gaiteiro da geração passada e assim sucessivamente embora sejam criadas novas melodias pelos atuais".

Perguntado sobre sua experiência no grupo Miro fala com emoção sobre sua primeira flauta feita pelo seu irmão, guardada até hoje, que também participou do grupo e foi seu grande incentivador, assim como seu pai, mas que faleceu. O falecimento de alguns componentes do grupo também foi motivo para a sua paralisação por quase um ano, mas que hoje segue forte em inúmeras apresentações. Miro fala ainda: “[...] para participar do grupo foi um tanto estranho e ao mesmo tempo engraçado, pois eu tinha apenas o interesse de aprender a tocar e não participar do grupo". Contudo a curiosidade foi maior e Miro começou a participar das reuniões. Entretanto, sua timidez foi seu grande vilão nas apresentações. Por fim, Miro afirma: "me sinto feliz por estar mantendo viva tão linda tradição que vem passando de geração em geração".

\section{CONSIDERAÇÕES FINAIS}

Para finalizar compreendo que a contribuição e participação do índio na formação da sociedade brasileira no que concerne a cultura enquanto aspectos que a envolvem como a culinária, remédios, vocabulário e danças. A delimitação do conceito de espaço e sua importância nas áreas abordadas: Geografia e Teatro para o entendimento da classificação das apresentações dos Cabocolinhos de Ceará Mirim como espaços de presença indígenas delimitados tanto fisicamente como culturalmente, e como espaço de representação cênica.

Desse modo, o espaço dos caboclinhos é caracterizado continua configuração e reconfiguração espacial-tempo no tocante as mais variadas culturas e costumes deixados e levados por gerações diante da trajetória temporal.

\section{REFERÊNCIAS}

1. ARRUDA, Indira. Blog O povo. Rio Grande do Norte: animação em Natal e na Paria da Ridinha. Disponível em: <http://blog.opovo.com.br/temporeal/2011/03/07/rio-grande-do-norteanimacao-em-natal-e-na-praia-da-redinha/>. Acesso em 15 janeiro 2011.

2. ARAÚJO, Sávio. Sobre as manifestações espetaculares. Natal: DEART - Laboratório de Cenografia, UFRN, 2003.

3. CARNEIRO, Edison. 2a ed. Folguedos Tradicionais. Rio de Janeiro: Funarte, 1982.

4. COMISSÃO NACIONAL DO FOLCLORE - CNF. Revista Brasileira de Folclore. Disponível em: <http://www.comissaonacionaldefolclore.org.br/>. Acesso em: 20 janeiro 2011.

5. CASCUDO, Luís da Càmara. Dicionário do Folclore Brasileiro. 10ạ ed. Rio de Janeiro: Ediouro, 1972. 
6. FRANÇA, Maria Edna Alves da Silva. Cabocolinhos de Ceará-Mirim: uma História Cultural. 2003. 70 f. Monografia ( Graduação em Ciências Sociais com habilitação em Antropologia)Universidade Federal do Rio Grande do Norte. Natal, 2003.

7. FUNDAÇÃO DE NACIONAL DO ÍNDIO- FUNAI. Os índios. Disponível em: <http://www.funai.gov.br/indios/conteudo.htm>. Acesso em: 2 janeiro 2011.

8. GURGEL, Déifilo. Espaço e tempo do folclore potiguar. 3a ed. Natal: Governo do Estado do Rio Grande do Norte, Departamento Estadual de Imprensa, 2001. Coleção Natal 400 anos.

9. MACHADO, Gibson. Acervo pessoal. Fotos da linha do tempo. Disponível em: <http://www.facebook.com/home.php\#!/media/set/?set=a.1298548760905.32674.1745986839 \&type=3>. Acesso em: 20 nov. 2012.

10. RAMOS, Fabio Pestana. Blog Para entender a História. A questão do cristianismo e do trabalho compulsório na América Portuguesa. Disponível em: <http://fabiopestanaramos .blogspot.com/2011/03/questao-do-cristianismo-e-do-trabalho.html>. Acesso em 10 janeiro 2011.

11. TAMDJIAM, James Onnig; MENDES, Ivan Lazzari. Geografia geral e do Brasil: estudos para compreensão do espaço: ensino médio/volume único. São Paulo: FTD, 2005.

12. TUAN, Yi-Fu. Espaço e lugar: a perspectiva da experiência. Tradução de Lívia de Oliveira. São Paulo: DIFEL, 1983.

13. UBERSFELD, Anne. L'Espacethéâtral [O Espaço Teatral]. Paris: CNDP, 1979. 